\title{
ACTIVATION OF A MODERn INDUSTRY
}

\author{
by
}

Ping Wang and Danyang Xie

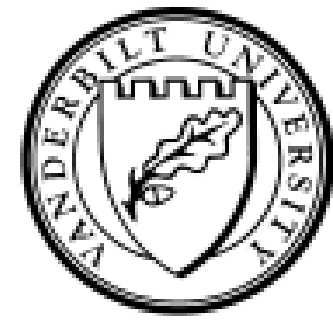

Working Paper No. 01-W35

December 2001

DEPARTMENT OF ECONOMICS

VANDERBILT UNIVERSITY

NASHVILLE, TN 37235

www.vanderbilt.edu/econ 


\title{
Activation of a Modern Industry
}

\author{
Ping Wang and Danyang Xie*
}

December 2001

\begin{abstract}
This paper constructs an integrated framework to disentangle the underlying economic mechanism of industrial transformation. We consider three essential elements for the analysis: skill requirements, industry-wide spillovers and degrees of consumption subsistence. We find that human and nonhuman resources, production factor matching and industrial coordination are all important for activating a modern industry. In the process of industrial transformation, job destruction may exceed job creation, and income distribution may get worse immediately following the activation of a modern industry. An array of policy prescriptions for advancing a poor country are provided.

JEL Classification Numbers: D24, O14, D33
\end{abstract}

*Ping Wang, Vanderbilt University and NBER; Danyang Xie, International Monetary Fund and Hong Kong University of Science and Technology. We have benefitted from discussion with Bob Driskill and Peter Howitt. The views expressed here are those of the authors and do not necessarily represent those of the IMF policy. 


\section{Introduction}

Over the past four decades, several East Asian newly industrialized countries (NICs) have experienced rapid growth and drastic industrial transformation. ${ }^{1}$ It is, however, often observed that some developing countries are always stuck with the traditional industries, unable to embark on modern industries that may spur economic advancement. What could be the barrier to activation of a modern industry? Are there any public policies that could overcome this barrier to entry? While the recent economic growth literature largely ignores the underlying process of creating a modern industry, conventional economic development studies lack a formal model to explain such a process. Our paper intends to examine these important issues within an optimizing framework that accounts for a number of important features concerning the industrialization of a developing economy. It may help to understand why some less-developed countries stay poor for a long time and why some development aid programs fail to advance a low-income economy. ${ }^{2}$

Earlier contributions in the theory of economic take-off and transformation include pivotal works by Lewis (1955), Rostow (1960), Rosenstein-Rodan

\footnotetext{
${ }^{1}$ For an illustration of the industrial transformation experiences in Japan, Korea, Taiwan and India, the reader is referred to Evans (1995). For micro patterns of job turnover and industrial productivity, see Roberts and Tybout (1996).

${ }^{2}$ In Morawetz (1981), an interesting case study is provided, illustrating why Columbian apparel producers failed in competition with East Asian economies. Easterly (2001) contains a wealth of examples of failed aid programs: Akosombo Dam in Ghana and Morogoro Shoe Factory in Tanzania. One of the worst examples is aid to Zambia. After US $\$ 2$ billion in aid, Zambia today is poorer than in 1960.
} 
(1961) and Tsiang (1964). One of the most important recent development along these lines is the big push theory revived by Murphy, Shleifer and Vishny (1989), Matsuyama (1991) and Chen and Shimomura (1998). In this literature, the existence of multiple equilibria imply that a big push may enable industrialization, moving from a bad to a good equilibrium, where the equilibrium selection process may depend on history and self-fulfilling prophecies. While these studies provide useful insight toward understanding why some countries took off successfully and some fell in the low-growth trap, an integrated framework that explicitly delineates the underlying microeconomic structure has not been fully developed. As a consequence, it is difficult to assess the various causes of delayed industrialization or to evaluate the effectiveness of a big push policy.

Generally speaking, industrial transformation features sectoral shifts (i) from low to high value-added goods, (ii) from agricultural and mining to manufacturing outputs (and services), and (iii) from labor intensive to capital, skill and technology intensive products. In the mid-1960s when (South) Korean and Taiwanese economies began to take off, Balassa (1972) observed that there was a rapid industrial transformation from import substituting sectors to nontraditional exporting sectors, which has been believed a key to their success in economic development. In fact, the nontraditional exportables exhibited all three features mentioned above. Over the period from 1953 to 1968, the leading manufacturing sectors in Korea and Taiwan, has been shifted from processed food, to textile and plywood, to chemical and metal products, and to electronics and machine tools. Such a continual creation of new ventures replacing obsolete sectors has reflected not only the nimbleness 
of entrepreneuers but also the effectiveness of development strategies. ${ }^{3}$

The present paper emphasizes that industrialization is a process of reallocating labor and capital to sectors with external increasing returns. In a recent work, Kaneda (1995) focuses on labor reallocation in economic development, stressing that such a process is gradual due to a demographic constraint. In their cross-country study, Dowrick and Gemmell (1991) find that the speed of labor transfer from traditional to modern sectors has been slow in less developed countries, which lends empirical support to the important role of labor reallocation in economic advancement. In our paper, the lack of education, investment funds and technology transfer is responsible for delaying the activation of a modern sector. These factors also help to explain why poor countries are poor: they self-select into an industry with inferior technology. The explanations are very different from those in Parente and Prescott (1999) where inferior technologies are used because a coalition of factor suppliers becomes the monopoly seller of input services, and from those in Peretto (1999) where the postponement of industrialization is due crucially to insufficient support for the expensive in-house $R \& D$ to enable the production in the modern sector. In addition, we incorporate the idea

\footnotetext{
${ }^{3}$ For detailed discussion of the development experiences in Korea and Taiwan, see Amsden (1989) and Kuo (1983), respectively. The reader may also be referred to Thorbecke and Wan (1999) for an extensive discussion on some successful development programs that have fostered the take-off of the Taiwanese economy. These include the $\$ 1.2$ billion U.S. aid from 1951 to 1965 allocated to infrastructure, as well as the high interest rate and light taxation policies in inducing a growing supply of funds. Moreover, the outstanding education and training programs have assisted the structural changes in Taiwan's labor force to accommodate rapid industrial transformation.
} 
underlying the Stone-Geary utility function assuming that traditional sector outputs are essential for survival, but modern sector products are not. This enables the possibility that the modern sector may be non-operative at the early stage of development. ${ }^{4}$

Thus, the central features of our paper are three folds. First, production in the modern industry requires high-skilled labor. Even when new technologies are available, via joint venture, technology transfer or imitation, application of such technologies cannot be successful without sophisticated knowledge. This provides an essential role for human capital to play in the process of economic transformation. Second, modern sector needs industrial coordination, due to either vertical/horizontal integration or industry-wide networking. These factors can be simply captured by the presence of uncompensated spillovers in the modern industry. This form of the Marshallian externality implies naturally that the profitability of producing the modern good relies on operating at a good scale, which is difficult to be met in a poor economy. Third, modern goods are not necessary for survival. This reflects the realistic characteristic of advanced products, which ensures a lower marginal valuation of the outputs of a modern industry at the early stage of economic development.

The main findings of our paper can be summarized as follows. First, we find that the activation of a modern sector requires not only resources of investment funding, skilled labor and new technology, but also appropriate matching between capital and labor, as well as industrial coordination to

\footnotetext{
${ }^{4}$ For empirical observations during the British industrialization, see Horrell (1996).
} 
overcome the scale barrier. Second, our results suggest an array of plausible policy prescriptions for successful industrial transformation, including shortterm foreign aids, technology transfer and immigration of skilled workers, as well as long-term saving incentives, education and R\&D. Third, we illustrate the possibility of short-term rise in unemployment at the time of activating a modern industry or during the entire process of industrialization, depending crucially on the relative scarcity between capital and skilled workers.

The rest of the paper is organized as follows. Section 2 presents a simple illustration of why a country may not be able to enter a modern industry. Section 3 uses a more realistic model to study policies that help activate the modern industry and the effect of such an activation on income distribution. Section 4 asks what will happen to the unemployment situation if the production technologies are Leontief. Section 5 concludes with suggestions on future research.

\section{A Simple Illustration}

In order to understand what could be the barrier to activating a modern industry, this section provide the basic intuition that drives the results in a simple model. We consider an economy that starts with a traditional industry employing capital and labor with a constant return to scale industry. A modern industry is then introduced, using an identical Cobb-Douglas technology except for the constant scaling factor. Under this simple setup, it is assumed that labor is homogeneous and capital is perfectly mobile between the two industries. Given limited human and nonhuman resources, we are 
asking under what conditions it is desirable to activate this modern industry. More realistic models that allow for departure from constant returns to scale and homogenous labor are delayed until Section 3 to deal with a richer set of questions such as, policies that help activate the modern industry and the effect of such an activation on income distribution. We further consider restricted factor substitution in Section 4 to discuss factor minsmatch and unemployment issues in the process of industrial transformation.

More specifically, the production functions in the traditional industry (industry 1) and the modern industry (industry 2) are given by,

$$
Y_{i}=A_{i} K_{i}^{\alpha} L_{i}^{1-\alpha}
$$

where $K_{i}, L_{i}$ and $Y_{i}$ are the capital inputs, labor inputs, and final output in industry $i$, respectively. At the moment, we assume that they share the same output elasticities $\alpha$ and $1-\alpha$ (or factor income shares), where $0<\alpha<1$. The sole difference between the technologies in the two industries is captured by the assumption that $A_{2}>A_{1}>0$, i.e., the modern industry uses an input saving technology. Letting $p$ denote the relative price of good 2 in unit of good 1, the real GNP is thus given by $G N P=Y_{1}+p Y_{2}$.

Labor is homogenous and is supplied inelastically:

$$
L_{1}+L_{2} \leq L
$$

where $L$ is the total labor supply in the economy. The resource constraint for the homogeneous capital goods is given by

$$
K_{1}+K_{2} \leq F,
$$


where $F$ is the total funding available for acquiring capital goods. The total funding is regarded as exogenous throughout the paper. This is made not only for simplicity but for flexibility to permit sources of funds that have been important in developing countries, such as via government allocation, foreign aid and direct foreign investment.

The preferences on the two industrial outputs are different. In particular, we assume that the output of the traditional industry is a necessity good (say, clothing) whereas that of the modern sector is a luxury good (say, a manufacturing good such as telephone or TV). Thus, the utility function can be specified as:

$$
\ln C_{1}+\ln \left(C_{2}+\theta\right)
$$

where $\theta>0$ indicates that $C_{2}$ is not a necessity good - it is a luxury good in the sense that its income elasticity is greater than one. During the process of economic development, one may capture the on-going increase in the standard of living by allowing the value of $\theta$ to decline over time. For example, while telephone and TV are luxurious in Korea and Taiwan forty years ago, even automobile and computer are almost necessities nowadays in these economies.

In this simple model, the market equilibrium is the same as the social optimum, which is easier to deal with. In the absence of international trade, we have: $C_{1}=Y_{1}$ and $C_{2}=Y_{2}$. Given the specification of the production and the utility functions, let us proceed to find the social optimum allocation of capital and labor by solving the following maximization problem:

$$
\max \ln \left[A_{1} K_{1}^{\alpha} L_{1}^{1-\alpha}\right]+\ln \left[A_{2} K_{2}^{\alpha} L_{2}^{1-\alpha}+\theta\right]
$$


subject to constraints (1) and (2). If both industries are operative, the firstorder conditions are standard and the assumption of common factor incomes shares implies equalization of capital labor ratio between the two industries, namely,

$$
\frac{K_{1}}{L_{1}}=\frac{K_{2}}{L_{2}}=\frac{F}{L} .
$$

The first-order condition on capital is,

$$
\frac{\alpha}{K_{1}}=\frac{\alpha A_{2} K_{2}^{\alpha-1} L_{2}^{1-\alpha}}{A_{2} K_{2}^{\alpha} L_{2}^{1-\alpha}+\theta} .
$$

which equalizes the marginal valuation of capital between the two industries. One can easily see that if $\theta=0$, total capital is divided equally between the two industries (as is the labor force).

In general, our specification yields full employment of both capital and labor, so both factor reallocation constraints, (1) and (2), must hold for equality in equilibrium. Substituting (3) as well as (1) and (2) with equality into (4), one obtains the solution for $K_{2}$ :

$$
\frac{1}{F-K_{2}}=\frac{A_{2}[F / L]^{\alpha-1}}{A_{2} K_{2}[F / L]^{\alpha-1}+\theta}
$$

and the solution is:

$$
K_{2}=\frac{1}{2} \frac{A_{2} F^{\alpha} L^{1-\alpha}-\theta}{A_{2} F^{\alpha-1} L^{1-\alpha}}
$$

We can now see that industry 2 will emerge if and only if

$$
A_{2} F^{\alpha} L^{1-\alpha}-\theta>0 \text {. }
$$

It appears that given technological parameters $A_{2}$ and $\alpha$, the developing country will be unable to enter the more advanced industry if the total funding and labor supply, adjusted by the technological factor, are insufficient 
to overcome the preference bias (i.e. if all the inputs are put in industry 2 and still unable to produce an output greater than $\theta$ ). Again, in this simple model, if $\theta=0$, industry 2 will always emerge.

Although the condition for entry (5) sends a clear message that the barrier results from a combination of both technological and preference parameters. It is nonetheless too simplistic. In the real world, many components of the two sides matter. In the next section, we introduce external effects and differentiated labor into our model and give a more complete analysis of the entry condition and discuss normative policy issues.

\section{External Effects and Differentiated Labor}

One of the important characteristic of the advanced industry is that its production function exhibits increasing returns to scale at the aggregate level. We model this aspect by resorting to the literature of Marshallian externality

in new growth theory (Romer 1987, Lucas 1988, Benhabib and Farmer 1994). In this section, we assume:

$$
Y_{1}=A_{1} K_{1}^{\alpha_{1}} L_{1}^{1-\alpha_{1}} ; \quad Y_{2}=A_{2} K_{2}^{\alpha_{2}} L_{2}^{1-\alpha_{2}} \bar{K}_{2}^{1-\alpha_{2}}
$$

where $K_{2}$ is the capital input in a representative firm and $\bar{K}_{2}$ is the industry average and is treated by individual firms as exogenously given. This sectorspecific Marshallian externality in firm capital captures learning from other entrepreneurs in production methods, in business management, as well as in 
marketing and networking. ${ }^{5}$ While both sectors exhibit constant returns in private inputs, the modern industry has increasing social returns as a result of uncompensated spillovers from industry-specific capital. It is natural to assume that the modern industry uses capital more intensively than the traditional industry in the private sense (without accounting for the external effect), i.e., $\alpha_{2}>\alpha_{1}$.

We further relax the homogeneous labor assumption allowing the economy to be populated by two types of workers, the low-skilled ones with mass $N_{1}$ and the high-skilled ones with mass $N_{2}$. While all workers can produce equally effectively in industry 1 , only the high-skilled can handle work in industry 2. That is,

$$
L_{2} \leq N_{2}
$$

Additionally, in contrast to the previous section, we assume that the relative price of type- 2 capital is greater than that of type-1. Namely, our funding constraint becomes,

$$
K_{1}+q K_{2} \leq F
$$

where $q>1$, the relative price, is exogenously given. In fact, a reduction in this relative price measure may capture investment subsidies, investment tax rebates and reductions in tariff on imported capital goods.

Let us first look at the competitive equilibrium. In the presence of the Marshallian externality in industry 2, the competitive equilibrium can be obtained from solving a pseudo social planner's problem by regarding the

\footnotetext{
${ }^{5}$ Alternatively, one may consider Marshallian externality in forms of human capital, as in Lucas (1988), or raw labor, as in Matsuyama (1991).
} 
external effect as given. Specifically, the optimization problem is to solve (P) modified for the new production technologies specified as in (6), subject to labor reallocation constraints (1) and (7), as well as the capital reallocation constraint (8). Denote by $M P K_{i}$ the marginal product of capital in sector $i$. If industry 2 is operative, the market allocation of capital must satisfy the equalization of the marginal valuation of capital:

$$
M P K_{1}=\frac{p}{q} M P K_{2} .
$$

Note that from consumption allocation efficiency, the relative price must be equal to the marginal rate of substitution between good 2 and good 1: $p=\frac{M U_{2}}{M U_{1}}=\frac{C_{1}}{C_{2}+\theta}$, or,

$$
p=\frac{A_{1} K_{1}^{\alpha_{1}} L_{1}^{1-\alpha_{1}}}{A_{2} K_{2} L_{2}^{1-\alpha_{2}}+\theta} .
$$

where $M U_{i}$ is the marginal utility of consumption good $i$. In deriving equation (10), we have used the equilibrium condition that $\bar{K}_{2}=K_{2}$.

Using (10), the capital allocation equation (9) can be re-arranged to yield:

$$
\frac{\alpha_{1}}{K_{1}}=\frac{\alpha_{2} A_{2} L_{2}^{1-\alpha_{2}}}{q\left[A_{2} K_{2} L_{2}^{1-\alpha_{2}}+\theta\right]}
$$

which reduces to the intuitive result: $K_{2} / K_{1}=1 / q$ if $\theta=0$ and $\alpha_{1}=\alpha_{2}$.

To study under what parameter restriction industry 2 fails to emerge, we use the capital allocation constraint (8) with equality to rewrite (11) as:

$$
\frac{\alpha_{1}}{K_{1}}=\frac{\alpha_{2} A_{2} L_{2}^{1-\alpha_{2}}}{A_{2}\left(F-K_{1}\right) L_{2}^{1-\alpha_{2}}+q \theta}
$$

which yields,

$$
K_{1}=\frac{\alpha_{1}}{\left(\alpha_{1}+\alpha_{2}\right)}\left[F+\frac{q \theta}{A_{2} L_{2}^{1-\alpha_{2}}}\right]
$$


This suggests that the fraction of capital allocated to industry $1\left(K_{1} / F\right)$ reduces as the total available funds $(F)$ or the labor allocated to industry 2 $\left(L_{2}\right)$ increases.

It is thus clear that industry 2 will remain non-operative if, $F-K_{1} \leq 0$, or, utilizing (12) and setting (7) with equality,

$$
\frac{\alpha_{1}}{F} \geq \frac{\alpha_{2} A_{2} N_{2}^{1-\alpha_{2}}}{q \theta} .
$$

This states that the reasons for the developing country to be stuck with industry 1 could be: too little funding ( small $F$ ), too few skilled labor (small $N_{2}$ ), imperfect copy of advanced technology ( $A_{2}$ not sufficient high), too expensive the type-2 capital (high $q$ ) and too high the preference bias (high $\theta$ ). This condition, however, is sufficient but not necessary, because it considers only capital but not labor reallocation - in other words, the country can be stuck with industry 1 even when (13) does not hold, if labor reallocation is taken into account.

To work out the necessary condition for industry 2 to remain inactive (or the sufficient condition for industry 2 to start off), we need to study labor reallocation by examining the relative wages in the two industries:

$$
\begin{aligned}
\frac{W_{2}}{W_{1}} & =p \frac{M P L_{2}}{M P L_{1}} \\
& =\frac{\alpha_{1}\left(1-\alpha_{2}\right)}{\left(1-\alpha_{1}\right) \alpha_{2}} \times \frac{q\left[K_{2} / L_{2}\right]}{\left[K_{1} / L_{1}\right]} \\
& =\frac{\alpha_{1}\left(1-\alpha_{2}\right)}{\left(1-\alpha_{1}\right) \alpha_{2}} \times\left[\frac{L-L_{2}}{L_{2}}\right]\left[\frac{\left(\alpha_{1}+\alpha_{2}\right) A_{2} L_{2}^{1-\alpha_{2}} F}{\alpha_{1}\left[A_{2} L_{2}^{1-\alpha_{2}} F+q \theta\right]}-1\right],
\end{aligned}
$$

where $M P L_{i}$ denotes the marginal product of labor in sector $i$, the second equality makes use of (9) and the third equality makes use of (12). That is, 
the wage ratio between the two industries is inversely related to the relative capital-intensity measure (the first term of the last expression) and the relative labor abundance (the second term of the last expression), but positively related to the relative capital abundance (the last term of the last expression) Notice that in the absence of skill differentiation and the Marshallian externality in industry 2 , factor price equalization holds and the capital-labor ratio would then depend solely on the relative price.

From the equation above, we can see that the relative wage is negative for low level of $L_{2}$ and will initially rise when $L_{2}$ increases but will eventually approach zero when $L_{2}$ approaches $L$. In other words, if we label the relative wage as $\Omega$, then

$$
\Omega\left(L_{2}\right)=\frac{\alpha_{1}\left(1-\alpha_{2}\right)}{\left(1-\alpha_{1}\right) \alpha_{2}} \times\left[\frac{L-L_{2}}{L_{2}}\right]\left[\frac{\left(\alpha_{1}+\alpha_{2}\right) A_{2} L_{2}^{1-\alpha_{2}} F}{\alpha_{1}\left(A_{2} L_{2}^{1-\alpha_{2}} F+q \theta\right)}-1\right]
$$

is increasing in $L_{2}$ if $\sup _{L_{2} \in(0, L)} \Omega\left(L_{2}\right) \leq 0$; it becomes hump-shaped if $\sup _{L_{2} \in(0, L)} \Omega\left(L_{2}\right)>0$.

If $\sup _{L_{2} \in(0, L)} \Omega\left(L_{2}\right)<1$, industry 2 will never emerge. In this case, a policy that increases the number of skilled workers (with $L$ fixed) will not jump start industry 2. Thus, at the early stage of development when the economy is extremely poor, policy instrument selection is crucial in the sense that accumulation of investment funds, rather than education, is necessary for a successful industrial transformation.

A more interesting case arises when $F$ and $A_{2}$ are high enough so that $\sup _{L_{2} \in(0, L)} \Omega\left(L_{2}\right)>1$. From the arguments above, the relative wage $\Omega\left(L_{2}\right)$ must now be hump-shaped. We can show that there exist $N_{2 l}<N_{2 h}$ such that (i) when $N_{2}<N_{2 l}$, industry 2 remains non-operative thus skilled workers 
all work in industry 1; (ii) when $N_{2}=N_{2 l}$, industry 2 is activated and skilled workers all work in industry 2 but wages are equal across the two industries; (iii) when $N_{2 l}<N_{2}<N_{2 h}$, skilled workers all work in industry 2, earning a wage greater than that in industry 1 ; (iv) when $N_{2}=N_{2 h}$, wage differential vanishes as in case (ii), but at a higher common wage level; (v) when $N_{2}>N_{2 h}$, we must have $L_{2}=N_{2 h}$ and skill mismatch occurs as the surplus skilled labor, $N_{2}-N_{2 h}$, work in industry 1 with wages equalized between the two industries. Of course, if case (v) occurs, the country should be contemplating the activation of a third and more advanced industry.

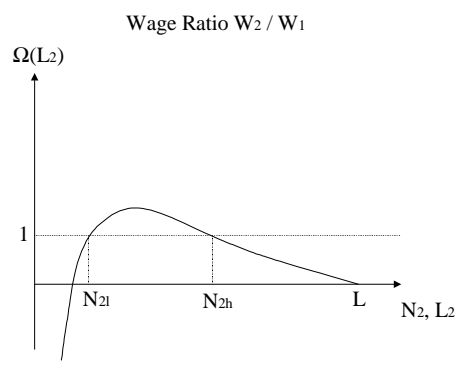

In case (i) where industry 2 remains inactive, there are two separate reasons. When $\Omega\left(N_{2}\right) \leq 0$, the condition is equivalent to (13) and in this case, limited resources from capital funding, labor and the modern technology result in lower marginal valuation of capital in industry 2. When $0<\Omega\left(N_{2}\right)<1$, there are enough resources to enable equalization of the marginal valuation of capital, though it leads to a relative wage which is too low for skilled workers to participate in industry 2. Summarizing, the activation of a modern industry requires not only sufficient resources of capital funds, skilled labor 
and new technologies, but also appropriate matches between capital and labor to ensure profitability of every factor reallocation in a competitive fashion.

Another observation we can make from the diagram is that as $N_{2}$ increases above $N_{2 l}$ as the modern industry begins to operate, the income distribution gets worse initially. To understand this phenomenon, note that the output of the modern sector is a luxury good. An increase in $N_{2}$ generates a positive wealth effect, thus raising the relative demand for the modern good and encouraging capital reallocation from the traditional to the modern sector. As a result of capital-labor complementarity (in the Pareto sense), the relative wage rises (which can be seen from the second square bracket in equation (14)). As $N_{2}$ increases further toward $N_{2 h}$, income distribution improves eventually as the skilled labor becomes sufficiently abundant (which can be seen from the first square bracket in equation (14)). If industry 3 is not activated when $N_{2}$ continues to increase, some skilled labor has to work in industry 1 and the wage differential disappears.

The existence of external effect implies that although an individual firm has no incentive to embark on a type- 2 goods production unilaterally, the society as a whole may find such activity welfare enhancing. To see this possibility, note that for the society as a whole, the marginal product of type- 2 capital is $A_{2} L_{2}^{1-\alpha_{2}}$. Hence, if

$$
\frac{A_{2} N_{2}^{1-\alpha_{2}}}{q \theta}>\frac{\alpha_{1}}{F}>\frac{\alpha_{2} A_{2} N_{2}^{1-\alpha_{2}}}{q \theta},
$$

an output subsidy to type- 2 goods production at the rate of $1 / \alpha_{2}-1$, financed by a lump-sum tax, may activate industry 2 and raise the repre- 
sentative agent's welfare. Of course, if this rate of subsidy fails to push $N_{2}>N_{2 l}$, a sufficiently higher rate that artificially jumps start industry 2 , is not necessarily welfare improving due to the distortions involved. In this case, the short-term solutions include (i) receiving external assistance from international organizations to raise $F$ (e.g., European Investment Bank loans and the U.S. Aid), (ii) obtaining technological transfer from developed countries to advance $A_{2}$, and (iii) attracting immigrants of high skill to increase $N_{2}$. The long-term solutions are (i) better education to raise the mass of skilled workers, (ii) greater saving incentives to increase available funds, and (iii) more R\&D investments to improve new technologies. Many of these programs have been implemented by developing countries (see, for example, those discussed in Thorbecke and Wan (1999) attributing to the 'Taiwan Miracle'). The radical measure may be to advertize the modern way of life, which reduces $\theta$ by turning a luxury good to a necessity good.

What can we say about the behavior of relative price, $p$ ? Can our theory lend support to the observed price trend? Focusing on the most relevant case when the modern industry is operating and there is no skill mismatch $\left(N_{2 l}<N_{2}<N_{2 h}\right)$, all skilled workers are employed in the modern industry. From (10), (11) and (12), the formula determining the relative price $p$ is given by,

$$
p=\frac{q \alpha_{1} A_{1}\left(L-N_{2}\right)^{1-\alpha_{1}}}{\alpha_{2} A_{2}^{\alpha_{1}} N_{2}^{\alpha_{1}\left(1-\alpha_{2}\right)}\left[\frac{\alpha_{1}}{\alpha_{1}+\alpha_{2}}\left(q \theta+F A_{2} N_{2}^{1-\alpha_{2}}\right)\right]^{1-\alpha_{1}}} .
$$

Obviously, as $A_{2}$ rises or $q$ declines, the supply of goods 2 increases and hence the relative price decreases. More interestingly, as more skilled labor is available, through the Rybczynski magnification effect goods 2 becomes 
more abundant, thus lowering the relative price. This finding is consistent with both time series and cross-section evidence that relative price of luxury goods falls during the process of development.

\section{Unemployment}

In previous sections, factor substitutability is assumed to function so that there is never any unemployment. Skill mismatch - high-skilled workers work in low-skilled industry - is possible when the modern industry does not operate (or when skilled workers are abundant but short of activating a third industry). In the real world, however, developing countries may have massive unemployment. This led us to conduct an analysis of industrial transformation in an environment where full employment may break down. The conventional literature of unemployment usually departs from the Walrasian setup, such as to consider search frictions or incomplete labor contract. For comparison purposes, we prefer to address the issue within the perfect competition framework under fixed proportion production technologies.

In particular, we assume the production technologies to take the Leontief forms:

$$
Y_{i}=A_{i} \min \left\{K_{i}, \gamma_{i} L_{i}\right\}, i=1,2
$$

where $A_{2}>A_{1}$ and $\gamma_{2}<\gamma_{1}$. In other words, type- 2 capital is more productive and industry 2 production is more capital intensive. For simplicity, we abstract from the consideration of the external effect in the modern sector

A model with Leontief technology is cumbersome to handle. But since 
our focus is on developing countries, we can safely restrict our attention to the case that

$$
\min \left\{K_{1}, \gamma_{1} L_{1}\right\}=K_{1}
$$

That is, unskilled labor is abundant and capital is relatively scarce in industry 1. We can not make the same assumption for industry 2 , however, because skilled labor may be more scarce than type-2 capital. Thus, we need to study two separate cases, while the equilibrium solution is an appropriate selection from the two cases, depending on the availability of investments funds and skilled workers.

\subsection{Capital Scarcity in the Modern Industry}

When capital binds in the modern industry, we have $\min \left\{K_{2}, \gamma_{2} L_{2}\right\}=K_{2}$. In the absence of distortions or externalities, the competitive equilibrium is the same as the social optimum. The central planner's problem is given by,

$$
\max \ln \left(A_{1} K_{1}\right)+\ln \left[A_{2} K_{2}+\theta\right]
$$

subject to (8). Utilizing (8) with equality, we can manipulate the first-order condition to obtain:

$$
\frac{1}{F-q K_{2}}=\frac{A_{2}}{q\left[A_{2} K_{2}+\theta\right]}
$$

which leads to,

$$
K_{1}=\frac{A_{2} F+q \theta}{2 A_{2}} ; \quad K_{2}=\frac{A_{2}[F / q]-\theta}{2 A_{2}} .
$$

Thus in order for industry 2 to emerge, the condition we need is,

$$
A_{2}[F / q]>\theta
$$


which has the same flavor and interpretation as condition (5).

When the above condition is met, the fixed proportion production technologies imply:

$$
L_{1}=\frac{A_{2} F+q \theta}{2 A_{2} \gamma_{1}} ; \quad L_{2}=\frac{A_{2}[F / q]-\theta}{2 A_{2} \gamma_{2}} .
$$

Thus, in order to support this case where capital is relatively scarce in both industries, we need:

$$
N_{1} \geq \frac{A_{2} F+q \theta}{2 A_{2} \gamma_{1}} \text { and } N_{2} \geq \frac{A_{2}[F / q]-\theta}{2 A_{2} \gamma_{2}} .
$$

In this case, unemployment may occur:

$$
u_{1}=N_{1}-\frac{A_{2} F+q \theta}{2 A_{2} \gamma_{1}} ; \quad u_{2}=N_{2}-\frac{A_{2}[F / q]-\theta}{2 A_{2} \gamma_{2}}
$$

where $u_{1}$ and $u_{2}$ are unemployment of unskilled and skilled, respectively. Total unemployment $u$ is therefore given by,

$$
u=L-\frac{1}{2}\left[F\left(\frac{1}{\gamma_{1}}+\frac{1}{q \gamma_{2}}\right)-\frac{\theta}{A_{2} \gamma_{1} \gamma_{2}}\left(\gamma_{1}-q \gamma_{2}\right)\right]
$$

Let us run a thought experiment. Suppose at the beginning, the developing country falls a little short of enough funding to activate the modern industry. The unemployment is then given by $L-F / \gamma_{1}$. If an aid, $G$, is received so that industry 2 barely goes into existence, the unemployment will rise because industry 2 creates less employment than industry 1 loses, for two reasons: (i) industry 2 is more capital intensive; and, (ii) type-2 capital is more expensive. Both imply that there must be sufficiently large amount of capital moved out of industry 1 , thus inducing substantial job destruction 
in the traditional sector. This can be referred to as the creative destruction effect of industrialization. Only when the aid is substantially high to allow the developing country to operate industry 2 at a good scale will the unemployment fall.

Since capital is scarce in this case, it is clear that once the modern sector is operative, additional increases in investment funds always result in less unemployment, as it can be seen from (19). That is, once the modern industry is operative, there will be no more creative destruction in jobs. Consider now only the case where industry 2 is operative. When $\gamma_{2}$ increases, i.e., production of the modern good uses capital more intensively, capital scarcity becomes more severe. As a consequence, both the unemployment in industry 2 and the total unemployment rise, but the unemployment rate in the traditional sector remains unchanged (see equation (18)). This explains, in part, why in many socially planned economies, misallocation of funds to some heavy industries may be a costly and painful process. ${ }^{6}$

When $\theta$ decreases, i.e., what used to be the luxury good becomes less so, it encourages capital reallocation from the traditional sector, industry 1 , to the modern sector, industry 2 (see equation (16)). Under the fixed proportion technologies, demand for unskilled workers decreases whereas demand for skilled workers rises, thereby leading to higher unemployment in industry 1 but less in industry 2. Its effect on total unemployment is ambiguous, depending on the sign of $\left(\gamma_{1}-q \gamma_{2}\right)$. In particular, recall that $\gamma_{2}<\gamma_{1}$ and $q>1$. Total unemployment rises (falls) as $\theta$ decreases if the difference

\footnotetext{
${ }^{6}$ For example, see a discussion of the case of China over the period $1952-80$ by Chow
} (1993). 
in capital intensity is small (large) and the capital cost differential is large (small). Thus, to accomplish a successful industrial transformation, one must take into account the transitional cost of unemployment during the process of sector shifts. The above result provides a clear-cut analysis in evaluating such a cost.

\subsection{Skilled Labor Scarcity in the Modern Industry}

We next turn to the case where skilled labor binds in the modern industry, we have $\min \left\{K_{2}, \gamma_{2} L_{2}\right\}=\gamma_{2} L_{2}$. In this case, skilled labor is relatively scarce in industry 2. The central planner's problem now becomes,

$$
\max \ln \left(A_{1} K_{1}\right)+\ln \left[A_{2} \gamma_{2} L_{2}+\theta\right]
$$

subject to (7) and the capital reallocation constraint,

$$
K_{1}+q \gamma_{2} L_{2} \leq F
$$

Since the skilled labor binds in industry 2, monotonicity of the preferences implies the equilibrium level of industry 2 employment must be at $L_{2}=N_{2}$, which can then be substituted into (20) with equality to yield:

$$
K_{1}=F-q \gamma_{2} N_{2}
$$

and,

$$
L_{1}=\frac{F-q \gamma_{2} N_{2}}{\gamma_{1}}
$$

This is an equilibrium if the solution fulfils the presumption that unskilled labor is relative abundant, i.e., $\gamma_{1}\left(L-N_{2}\right) \geq K_{1}$. Using (22), this condition 
becomes:

$$
\gamma_{1} L \geq F+\left(\gamma_{1}-q \gamma_{2}\right) N_{2}
$$

In this case, industry 2 reaches full employment and unemployment may occur only in industry 1 , which is given by,

$$
\begin{aligned}
u & =L-N_{2}-L_{1} \\
& =L-F / \gamma_{1}-\left(\gamma_{1}-q \gamma_{2}\right) N_{2} / \gamma_{1}
\end{aligned}
$$

Three points deserve further elaboration. First, as long as $N_{2}>0$ and condition (23) is met, industry 2 always operates, yet its scale is limited due to the scarcity of skilled workers. Second, if the difference in capital intensity is sufficiently small and the capital cost differential is sufficiently large such that $\gamma_{1}-q \gamma_{2}<0$, an increase in the skilled labor may suck too much capital to industry 2 so that the loss of employment in industry 1 is larger than jobs created in industry 2, leading to a higher unemployment rate. In contrast to the previous case where capital funding is more scarce than the skilled labor, this creative destruction effect occurs even when the modern industry is operative. In this case, foreign aid programs may become essentially ineffective, as in several African examples studied by Easterly (2001). Instead, educational and training programs may better suit the need, leading to a successful modernization.

Finally, while an increase in $F$ or a decrease in $\gamma_{2}$ still reduce unemployment unambiguously, the effect of $\theta$ disappears. This is in stark contrast to previous case when capital is binding in the modern industry. Intuitively, since the skilled labor is scarce in production of the modern good, capital is 
always employed at a fixed proportion to the supply of skilled workers. This removes the potential trade-off in the reallocation of capital. As a result, whether the modern good is more necessary for survival does not matter to capital allocation or employment in the traditional industry, thus generating no effect on the unemployment rate.

\section{Conclusions}

In this paper, we have proposed an integrated framework to disentangle the underlying economic mechanism of industrial transformation. We have concluded that human and nonhuman resources, production factor matching and industrial coordination are all important for activating a modern industry. We have provided an array of short-term and long-term policy prescriptions for achieving a successful process of industrial evolution. Inappropriate implementation of development policy programs may fail to work and a poor country may stay backward.

Along these lines, a natural extension is to examine the dynamics of industrial evolution by allowing investment funds to accumulate. This enables a full characterization of the pattern of transitional growth of an economy in the process of industrialization. Another extension is to construct an n-sector model, where industries are ranked by the degrees of consumption subsistence and the measures of capital intensity. This can help understand the pattern of rises and falls of industries. In a normative point of view, it may be useful to consider endogenous trade-off between investment funds and skilled workers in the sense that by allocating funds to eduation or retraining, one may 
increase the fraction of skilled workers. Under this framework, one can study the welfare implications of public education programs.

There are several other avenues that may be interesting for future research. For brevity, we only mention two. On the one hand, one may incorporate a mechanism considered by Laitner (2000) that an economy's average propensity to save rises endogenously in the process of industrialization. In this case, growth can be sustained in the modern sector in which the perpetually growing funds enable perpetual accumulation of the capital stock. On the other hand, one may also follow Jovanovic (1998) or Wan (2001) to allow workers matched with high-quality capital or more profitable firms to have greater incentive to acquire marketable skills. This will then endogenize the evolution of human capital, leading to further industrialization. 


\section{References}

[1] Amsden, Alice H. (1989), Asia's Next Giant: South Korea and Late Industrialization, Oxford, UK, and New York, NY: Oxford University Press.

[2] Balassa, Bela (1972). "Industrial Policies in Taiwan and Korea," in L. Di Marco (ed.), International Economics and Development, New York, NY and London, UK: Academic Press.

[3] Benhabib, Jess and Roger Farmer (1994), "Indeterminacy and Increasing Returns," Journal of Economic Theory, 63, 19-41.

[4] Chen, Been-Lon and Koji Shimomura (1998), "Self-fulfilling Expectations and Economic Growth: A Model of Technology Adoption and Industrialization," International Economic Review, 39(1), 151-170.

[5] Chow, Gregory C. (1993), "Capital Formation and Economic Growth in China," Quarterly Journal of Economics, 108(3), 809-842.

[6] Dowrick, Steve and Norman Gemmell (1991), "Industrialisation, Catching Up and Economic Growth: A Comparative Study across the World's Capitalist Economies," Economic Journal, 101(1), 263-275.

[7] Easterly, William (2001), The Elusive Quest for Growth, Cambridge, MA: MIT Press.

[8] Evans, Peter (1995), Embedded Autonomy: States and Industrial Transformation, Princeton, NJ: Princeton University Press.

[9] Horrell, Sara (1996), "Home Demand and British Industrialization," Journal of Economic History, 56(3), 561-604.

[10] Jovanovic, Boyan (1998), "Vintage Capital and Inequality," Review of Economic Dynamics, 1(2), 497-530. 
[11] Kaneda, Mitsuhiro (1995), "Industrialization under Perfect Foresight: A World Economy with a Continuum of Countries," Journal of Economic Theory, 66(2), 437-462.

[12] Kuo, Shirley W. Y. (1983), The Taiwan Economy in Transition, Boulder, CO: Westview Press.

[13] Laitner, John (2000), "Structural Change and Economic Growth," Review of Economic Studies, 67(3), 545-561.

[14] Lewis, Arthur (1955), The Theory of Economic Growth, London, UK: Allen and Unwin.

[15] Lucas, Robert E. Jr. (1988), "On the Mechanics of Economic Development," Journal Monetary Economics, 22(1), 3-42

[16] Matsuyama, Kiminori (1991), "Increasing Returns, Industrialization and Indeterminacy of Equilibrium," Quarterly Journal of Economics, 106(2), 617-650.

[17] Morawetz, David (1981). Why the Emperor's New Clothese are not Made in Columbia: A Case Study of Latin American and East Asian Manufacturing Exports, New York, NY, and Oxford, UK: Oxford University Press.

[18] Murphy, Kevin M., Andrei Shleifer and Robert W. Vishny (1989), "Industrialization and the Big Push," Journal of Political Economy, 97(5), 1003-1026.

[19] Parente, Stephen L. and Edward C. Prescott (1999), "Monopoly Rights: A Barrier to Riches," American Economic Review, 89(5), 1216-1233.

[20] Peretto, Pietro F. (1999), "Industrial Development, Technological Change and Long-Run Growth," Journal of Development Economics, 59(2), 389-417. 
[21] Robert, Mark J. and James R. Tybout (eds.) (1996), Industrial Evolution in Developing Countries: Micro Patterns of Turnover, Productivity and Market Structure, Oxford, UK, and New York, NY: Oxford University Press.

[22] Romer, Paul (1986), "Increasing Returns and Long-Run Growth," Journal of Political Economy, 94(6), 1002-1037.

[23] Rosenstein-Rodan, Paul N. (1961), "Notes on the Theory of the 'Big Push'," in Howard S. Ellis (ed.), Economic Development for Latin America, London, UK: Macmillan, 57-66.

[24] Rostow, Walt W. (1960), The Stage of Economic Growth, Cambridge, UK: Cambridge University Press.

[25] Thorbecke, Erik and Henry Wan, Jr. (eds.) (1999), Taiwan's Development Experience: Lessons on Roles of Government and Market, Norwell, MA and Dordrecht, NE: Kluwer Academic Publishers.

[26] Tsiang, S. C. (1964), "A Model of Economic Growth in Rostovian Stages," Econometrica, 32(4), 619-648.

[27] Wan, Henry Y., Jr. (2001), "Endogenous Growth Theory and Industrial Policy," Working Paper, Cornell University. 